\title{
Downregulation of VEGF mRNA expression by triamcinolone acetonide acetate-loaded chitosan derivative nanoparticles in human retinal pigment epithelial cells
}

\author{
This article was published in the following Dove Press journal: \\ International Journal of Nanomedicine \\ 21 August 2012 \\ Number of times this article has been viewed
}

\author{
Huaisheng Zhou' \\ Liqun Yang ${ }^{2, *}$ \\ Huajie $\mathrm{Li}^{2}$ \\ Haijun Gong' \\ Liangzheng Cheng ${ }^{2}$ \\ Haisheng Zheng' \\ Li-Ming Zhang ${ }^{2}$ \\ Yuqing Lan ${ }^{1, *}$ \\ 'Department of Ophthalmology, \\ Sun Yat-sen Memorial Hospital of \\ Sun Yat-sen University, ${ }^{2}$ Institute of \\ Polymer Science, School of Chemistry \\ and Chemical Engineering, Key \\ Laboratory of Designed Synthesis and \\ Application of Polymer Material, Key \\ Laboratory for Polymeric Composite \\ and Functional Materials of Ministry \\ of Education, Sun Yat-sen University, \\ Guangzhou, China \\ *Both corresponding authors \\ contributed equally to this work
}

Correspondence: Liqun Yang Institute of Polymer Science, School of Chemistry and Chemical Engineering, Key Laboratory of Designed Synthesis and Application of Polymer Material, Key Laboratory for Polymeric Composite and Functional Materials of Ministry of Education, Sun Yat-sen University, Guangzhou 510275, China

Tel +862084II 0934

Email yanglq@mail.sysu.edu.cn

Yuqing Lan

Department of Ophthalmolgy, Sun Yatsen Memorial Hospital of Sun Yat-sen University, Guangzhou 510120, China. $\mathrm{Tel}+86-20-8 \mathrm{I} 3320 \mathrm{I} 2$.

Email lyqglp@163.com
Background: The purpose of this study was to investigate the downregulation of mRNA expression of vascular endothelial growth factor (VEGF) by triamcinolone acetonide acetate (TAA)-loaded chitosan nanoparticles in human retinal pigment epithelial cells.

Methods: TAA-loaded deoxycholic acid-modified chitosan (TAA/DA-Chit) nanoparticles were prepared via a self-assembly mechanism, and their morphology and zeta potential were examined by transmission electron microscopy and zeta potential analysis, respectively. DA-Chit and TAA/DA-Chit nanoparticle toxicity was evaluated using a Cell Counting Kit-8 assay. The efficiency of cellular uptake was determined using fluorescein isothiocyanate-labeled DA-Chit nanoparticles, in place of TAA/DA-Chit nanoparticles, assessed by both inverted fluorescence microscopy and flow cytometry. Downregulation of VEGF mRNA expression by TAA/DAChit nanoparticles was further investigated by real-time reverse transcription polymerase chain reaction (RT-PCR) assay of the treated human retinal pigment epithelial cells.

Results: TAA/DA-Chit nanoparticles were prepared with a TAA-loading capacity in the range of $12 \%-82 \%$, which increased the water solubility of TAA from $0.3 \mathrm{mg} / \mathrm{mL}$ to $2.1 \mathrm{mg} / \mathrm{mL}$. These nanoparticles showed oblate shapes $100-550 \mathrm{~nm}$ in size in transmission electron microscopic images and had positive zeta potentials. The Cell Counting Kit- 8 assay indicated that the DAChit and TAA/DA-Chit nanoparticles had no toxicity and low toxicity, respectively, to human retinal pigment epithelial cells. Fluorescein isothiocyanate-labeled DA-Chit nanoparticle uptake by human retinal pigment epithelial cells was confirmed by inverted fluorescence microscopy and flow cytometry. Real-time RT-PCR assay showed that the VEGF mRNA level decreased after incubation of human retinal pigment epithelial cells with TAA/DA-Chit nanoparticles.

Conclusion: TAA/DA-Chit nanoparticles had a downregulating effect on VEGF mRNA expression in human retinal pigment epithelial cells and low cytotoxicity, which might be beneficial characteristics for the development of future treatment for diabetic retinopathy.

Keywords: chitosan, nanoparticle, triamcinolone acetonide acetate, human retinal pigment epithelial cells, vascular endothelial growth factor, mRNA

\section{Introduction}

Diabetic retinopathy is a common complication of diabetes that can cause retinal damage eventually leading to blindness, ${ }^{1-3}$ and retinal neovascularization is regarded as an important cause of this complication. ${ }^{4,5}$ Because vascular endothelial growth factor (VEGF) is a potent angiogenic factor, playing a crucial role in the development of retinal neovascularization, ${ }^{6-9}$ control of VEGF expression has been 
considered key to the treatment of diabetic retinopathy. ${ }^{4}$ The corticosteroid, triamcinolone acetonide, is an important antiangiogenic and anti-inflammatory agent, which is known to block neovascularization, vein occlusion, and macular edema effectively under clinical and pathophysiologic conditions. ${ }^{10-12}$ The inhibitory effect of triamcinolone acetonide on VEGF upregulation in ocular pathology has been reported in previous studies. ${ }^{13,14}$ It has also been reported that intravitreal triamcinolone acetonide brings about functional and anatomic improvement in patients with diabetic retinopathy, and particularly diabetic macular edema, ${ }^{10,15}$ but these effects are transient and reinjection is often necessary due to rapid metabolism and extremely low solubility in water. ${ }^{10}$ This process is usually associated with several undesirable complications, including glaucoma and endophthalmitis. ${ }^{16,17}$ Controlled release of this corticosteroid is thus important in achieving a sustained pharmacologic effect and overcoming the drawbacks of the procedure.

In recent years, interest has grown in amphiphilic polysaccharide derivatives, which have been used in the formulation of micellar nanoparticles used as hydrophobic drug delivery vehicles. ${ }^{18,19}$ Amphiphilic polysaccharide derivative nanoparticles are self-assemblies composed of hydrophobic microdomains and amphiphilic shells of polysaccharides in aqueous media. ${ }^{19,20}$ Hydrophobic drugs can be entrapped in these hydrophobic microdomains via hydrophobic interactions, while controlled release of the loaded drug can be achieved through diffusion from the nanoparticles or by biodegradation of amphiphilic polysaccharide derivatives. ${ }^{19}$

Chitosan, as a cationic polysaccharide, has attracted much attention in ophthalmology for ocular therapeutics due to its favorable biological properties, including good biocompatibility, biodegradability, low toxicity, mucoadhesiveness, and antibacterial activity. ${ }^{21,22}$ In the present study, using triamcinolone acetonide acetate (TAA) as a corticosteroid drug, ${ }^{23}$ TAA-loaded chitosan derivative (TAA/DA-Chit) nanoparticles were prepared through a selfassembly mechanism. The cytotoxicity of DA-Chit and TAA/ DA-Chit nanoparticles was evaluated using the Cell Counting Kit-8 (CCK-8) assay in human retinal pigment epithelial cells. Cellular uptake efficiency was investigated using fluorescein isothiocyanate labeled DA-Chit (FITC/DA-Chit) nanoparticles, instead of TAA/DA-Chit nanoparticles, by both inverted fluorescence microscopy and flow cytometry. According to the literature, ${ }^{16}$ proliferative vitreoretinopathy can be characterized by a proliferation of retinal pigment epithelial cells. Therefore, downregulation of VEGF mRNA expression by TAA/DA-Chit nanoparticles was assessed via real-time reverse transcription polymerase chain reaction (RT-PCR) in human retinal pigment epithelial cells through the controlled release of TAA.

\section{Materials and methods Materials}

Chitosan with an average molecular weight of $450 \mathrm{kDa}$ and $90.0 \%$ deacetylation was purchased from Shanghai Bo'ao Biological Technology Co, Ltd (Shanghai, China). Deoxycholic acid was obtained from Acros Organics Corp (Antwerp, Belgium). $N$-(3-dimethylaminopropyl)- $N$-ethylcarbodiimide hydrochloride (EDC) was purchased from Shanghai Medpep Co, Ltd (Shanghai, China). FITC was sourced from SigmaAldrich (St Louis, MO). TAA injection solution was purchased from Shanghai Tongyong Pharmaceutical Co, Ltd (Shanghai, China). One milliliter of TAA injection solution (40 mg TAA) was added to $10 \mathrm{~mL}$ of distilled water by stirring and then centrifuged at $3000 \mathrm{rpm}$ for 5 minutes. This precipitation process was repeated again, and the resulting solid was then dried at $45^{\circ} \mathrm{C}$ under vacuum for 24 hours. All other reagents were analytical grade and used as received.

\section{Synthesis and characterization of DA-Chit}

DA-Chit was synthesized in the manner reported in the literature. ${ }^{24}$ Briefly, $0.2 \mathrm{~g}$ of chitosan was dissolved in $20 \mathrm{~mL}$ of $1 \%$ aqueous acetic acid solution ( $\mathrm{pH}$ about 3 ) and diluted with $20 \mathrm{~mL}$ of ethanol. Deoxycholic acid $(0.85 \mathrm{~g}, 2.17 \mathrm{mmol})$ and EDC (0.62 g, $3.26 \mathrm{mmol})$ were added to the chitosan solution successively with stirring, and the reaction was allowed to proceed at room temperature for 24 hours. The reaction mixture was then poured into $60 \mathrm{~mL}$ of methanol/ ammonia solution $(7 / 3, \mathrm{v} / \mathrm{v})$ and centrifuged at $3500 \mathrm{rpm}$ for 10 minutes, followed by lyophilization of the precipitate to yield the DA-Chit product.

Fourier transform infrared (FTIR) analysis was performed using an FTIR analyzer (Nicolet/Nexus 670, Thermo Nicolet Corp, Madison, WI) at a resolution of $4 \mathrm{~cm}^{-1}$ using the $\mathrm{KBr}$ method. ${ }^{1} \mathrm{H}$ NMR was carried out on an NMR spectrometer (Mercury-Plus 300, Varian Medical Systems Inc, Palo Alto, $\mathrm{CA}$ ) at room temperature using $\mathrm{D}_{2} \mathrm{O}$ as the solvent. The signal at $\delta 2.22 \mathrm{ppm}$ for acetone in $\mathrm{D}_{2} \mathrm{O}$ was used as the external standard. ${ }^{25}$

\section{Preparation and properties of TAA/ DA-Chit and DA-Chit nanoparticles}

TAA was dissolved in a small amount of tetrahydrofuran and then added dropwise to the swollen DA-Chit by distilled 
water (prepared as described below). After dropwise addition of distilled water, as a selective solvent of DA-Chit for removal of tetrahydrofuran, a solution containing TAA/ DA-Chit nanoparticles was produced. Based on our previous work, ${ }^{19}$ the mechanism of preparation of TAA/DA-Chit nanoparticles is explained as entailing gradual entrapment of TAA molecules into the hydrophobic microdomains of DA-Chit micelles via self-assembly in the tetrahydrofuran/ distilled water mixture.

DA-Chit $10 \mathrm{mg}$ was swollen in $3 \mathrm{~mL}$ of distilled water by gently shaking for about 2 hours, and then a solution containing $2,4,6,8$, or $10 \mathrm{mg}$ of TAA in $0.3 \mathrm{~mL}$ of tetrahydrofuran was added with stirring. Next, $1 \mathrm{~mL}$ of distilled water was slowly added dropwise and the mixture was stirred for 24 hours. After tetrahydrofuran was evaporated by heating at $40^{\circ} \mathrm{C}$, the resulting solution was centrifuged at $5000 \mathrm{rpm}$ for 5 minutes, yielding a supernatant containing TAA/DA-Chit nanoparticles. The precipitate containing unloaded TAA was dissolved in $20 \%$ ethanol/phosphate-buffered solution (v/v, pH 6.2) solution, and its concentration was analyzed by ultraviolet-visible spectrophotometry (UV-3150, Shimadzu Corp, Kyoto, Japan) at $240 \mathrm{~nm}$. Standard TAA solutions were prepared at concentrations ranging from $0.73 \mu \mathrm{g} / \mathrm{mL}$ to $22 \mu \mathrm{g} / \mathrm{mL}$, and the correlation coefficient value $\left(R^{2}\right)$ was at least 0.999 . The loading capacity was calculated using equation (1).

$$
\text { Loading capacity }(\%)=[(\mathrm{A}-\mathrm{B}) / \mathrm{C}] \times 100
$$

where A is the total weight of TAA used, B is the weight of unloaded TAA in the precipitate after centrifugation, and $\mathrm{C}$ is the weight of DA-Chit. DA-Chit nanoparticles were prepared by dissolving $10 \mathrm{mg}$ of DA-Chit in $4 \mathrm{~mL}$ of distilled water and stirring for 2 hours, and then maintained them at room temperature for 24 hours.

\section{Measurement of zeta potential}

The zeta potentials of the TAA/DA-Chit nanoparticles in distilled water were measured in triplicate using a ZetaPALS zeta potential analyzer (Brookhaven Instruments Corp, Holtsville, NY) at $25^{\circ} \mathrm{C}$ with a $90^{\circ}$ scattering angle.

\section{Transmission electron microscopy observation}

The morphology of TAA/DA-Chit nanoparticles was investigated using transmission electron microscopy. A sample solution was dropped on a carbon-coated 200 mesh copper grid, air-dried, and then negative-dyed with a phosphotungstic acid solution (about $2 \mathrm{wt} \%$ ) for 30 seconds. The morphology of the micelles was then observed using a
JEM-1400 high contrast transmission electron microscope (JEOL Ltd, Tokyo, Japan).

\section{Cell culture}

D407 human retinal pigment epithelial cells were provided by the ophthalmic laboratory at the Zhongshan Ophthalmic Center of Sun Yat-sen University, and the study was approved by the ethics committee at Sun Yat-sen Memorial Hospital. They were grown in a $1 / 1(\mathrm{v} / \mathrm{v})$ mixture of Dulbecco's modified Eagle's and Ham's F12 medium (DMEM-F12, HyClone Laboratories Inc, Logan, UT) containing 10\% fetal bovine serum (Biological Industries, Kibbutz Beit Haemek, Israel) and antibiotic mixtures of $100 \mathrm{U} / \mathrm{mL}$ penicillin $\mathrm{G}$ and $100 \mu \mathrm{g} / \mathrm{mL}$ streptomycin sulfate (InvitrogenGibco, Rockville, MD). The cultures were maintained in a humidified $5 \% \mathrm{CO}_{2}$ environment at $37^{\circ} \mathrm{C}$. All cells between the third to sixth passages were grown to $70 \%$ confluence for treatment.

Third-passage human retinal pigment epithelial cells were harvested and cultured on glass coverslips, and underwent a process involving a wash with phosphate-buffered solution $(\mathrm{pH} 7.4)$ and fixation with $4 \%$ paraformaldehyde for 10 minutes before subsequent staining in $10 \%$ phosphatebuffered Giemsa stain ( $\mathrm{pH}$ 7.2) for 10 minutes. For immunocytochemical staining, endogenous peroxidase was blocked by preincubating the fixed human retinal pigment epithelial cells in $3 \% \mathrm{H}_{2} \mathrm{O}_{2} /$ methanol for 30 minutes. Two antibodies and diaminobenzidine were purchased from $\mathrm{Wu}$ Han Boster Bioengineering Co, Ltd (Wuhan, China). A rat antimonoclonal antibody cytokeratin cocktail (AE1/AE3) was used for 24-hour primary antibody staining of human retinal pigment epithelial cells, following by incubation with a the second antibody of sheep antimouse antibody IgG for one hour, washing with phosphate-buffered solution, and counterstaining with diaminobenzidine. Unstained human retinal pigment epithelial cells were used as controls, and all cells were observed on a computer-interfaced Zeiss Axio Observer Z1 inverted microscope (Carl Zeiss Far East Co, Ltd, Hong Kong, China).

\section{Cytotoxicity assay}

Cytotoxicity of DA-Chit and TAA/DA-Chit nanoparticles was evaluated using the CCK- 8 assay. ${ }^{26}$ The human retinal pigment epithelial cells were seeded in 96-well plates at a density of $3.0 \times 10^{4}$ cells/well in $100 \mu \mathrm{L}$ of DMEM-F12 containing $10 \%$ fetal bovine serum and antibiotic mixtures, as described above, and were then cultured at $37^{\circ} \mathrm{C}$ for 24 hours. 


\section{Cytotoxicity of DA-Chit}

After medium replacement with fresh medium, DA-Chit solutions were added to each well to final concentrations of 0.25 , 0.5 , or $1.0 \mathrm{mg} / \mathrm{mL}$, with human retinal pigment epithelial cells lacking DA-Chit used as controls. After an additional 24 hours of incubation, the medium was replaced again and $10 \mu \mathrm{L}$ of CCK-8 solution (Dojindo Molecular Technologies Inc, Kumamoto, Japan) was added to each well. Following a further 3 hours of incubation, optical density (OD) was measured at $450 \mathrm{~nm}$ using a microplate reader (Wellscan MK3, Labsystem Dragon, Finland). Relative cell viability (\%) related to the control well was calculated using equation (2), with experiments performed five times.

$$
\text { Cell viability }(\%)=\left(\mathrm{OD}_{450-\mathrm{s}} / \mathrm{OD}_{450-\mathrm{c}}\right) \times 100
$$

where $\mathrm{OD}_{450-\mathrm{s}}$ and $\mathrm{OD}_{450-\mathrm{c}}$ were obtained in the presence and absence of DA-Chit, respectively.

\section{Cytotoxicity of TAA/DA-Chit nanoparticles}

After replacement with fresh medium, solutions of DA-Chit nanoparticles, TAA, and TAA/DA-Chit nanoparticles with a TAA-loading capacity of $29 \%$ were added to each well to final TAA and DA-Chit concentrations of $0.1 \mathrm{mg} / \mathrm{mL}$ and $0.33 \mathrm{mg} / \mathrm{mL}$, respectively. After the treated human retinal pigment epithelial cells were additionally incubated for one, 3 , and 5 days, the medium was replaced again, and $10 \mu \mathrm{L}$ of CCK-8 solution was added to each well. Following 3 hours of incubation, the $\mathrm{OD}_{450}$ was determined by a microplate reader and the relative cell viability was calculated as described above. All experiments were performed five times, with untreated cultured human retinal pigment epithelial cells used as controls.

\section{Cellular uptake efficiency of FITC-labeled DA-Chit nanoparticles}

FITC/DA-Chit nanoparticles were prepared to study their uptake efficiency in human retinal pigment epithelial cells. After dissolving $10 \mathrm{mg}$ of DA-Chit in $3 \mathrm{~mL}$ of distilled water by stirring for 24 hours, $1 \mathrm{~mL}$ of FITC solution $(2 \mathrm{mg} / \mathrm{mL})$ was added dropwise into the DA-Chit solution, which was then stirred for 24 hours and centrifuged at 20,000 rpm for 30 minutes. The resulting precipitate was diluted with distilled water to yield solutions containing FITC/DA-Chit nanoparticles at different concentrations.

Visual assessment of cellular nanoparticle uptake involved variations in nanoparticle concentration, incubation time, and post-treatment time. Here, human retinal pigment epithelial cells were seeded in 24-well plates at a density of $1.0 \times 10^{5}$ cells/well in $500 \mu \mathrm{L}$ of DMEM-F12 containing $10 \%$ fetal bovine serum and antibiotic mixtures, and cultured at $37^{\circ} \mathrm{C}$ for 24 hours. Images of the cells were observed using an inverted microscope as described above, after replacement with fresh medium and the following procedures. A solution of FITC/DA-Chit nanoparticles was added to each well to produce concentrations at $0.3,0.5$, or $1.0 \mathrm{mg} / \mathrm{mL}$, followed by 24 hours of incubation. A solution of FITC/DA-Chit nanoparticles $(1.0 \mathrm{mg} / \mathrm{mL})$ was then added to each well, followed by incubation for 3, 6, and 24 hours. Next, a solution of FITC/DA-Chit nanoparticles $(1.0 \mathrm{mg} / \mathrm{mL})$ was added to each well, followed by 24 hours of incubation, replacement with fresh DMEM-F12, and further incubation for one, 3 , and 5 days.

For flow cytometric analysis, the human retinal pigment epithelial cells were seeded in 6-well plates at a density of $4.0 \times 10^{5}$ cells/well in $2.0 \mathrm{~mL}$ of DMEM-F12 containing $10 \%$ fetal bovine serum and antibiotic mixtures, as described above, and cultured at $37^{\circ} \mathrm{C}$ for 24 hours. Following the first two steps of the incubation procedure described above, the cells were washed three times with $1 \mathrm{~mL}$ of phosphatebuffered solution ( $\mathrm{pH}$ 7.4) and harvested by trypsinization. The cell suspension was then introduced into a FACS Calibur flow cytometer (Becton Dickinson Biosciences, San Jose, $\mathrm{CA}$ ) and the data were collected as the mean fluorescent signal from $1.0 \times 10^{4}$ cells.

\section{VEGF mRNA expression efficiency by real-time RT-PCR}

To address cellular VEGF mRNA expression efficiency on exposure to the nanoparticles, human retinal pigment epithelial cells were seeded in 6-well plates at a density of $4.0 \times 10^{5}$ cells/well in $2 \mathrm{~mL}$ of DMEM-F12 containing $10 \%$ fetal bovine serum and antibiotic mixtures, as described above, and cultured at $37^{\circ} \mathrm{C}$ for 24 hours. After replacement with fresh medium, solutions of DA-Chit, TAA, and TAA/ DA-Chit nanoparticles (with a TAA-loading capacity of $29 \%$ ) were added to each well to final TAA and DA-Chit concentrations of $0.1 \mathrm{mg} / \mathrm{mL}$ and $0.33 \mathrm{mg} / \mathrm{mL}$, respectively; cells treated with only fresh medium served as controls. After an additional 24 hours of incubation, the medium was removed, the cells were collected for RNA extraction, and an ABI PRISM ${ }^{\circledR} 7500$ sequence detection system (Applied Biosystems, Life Technologies Corp, Carlsbad, CA) was used for real-time RT-PCR and data analysis.

Total RNA was isolated from human retinal pigment epithelial cells using TRIzol (Takara Bio Inc, Kyoto, Japan) according to the manufacturer's manual. cDNA was 
synthesized by reverse transcription from $1.0 \mu \mathrm{g}$ of total RNA. In parallel, with standard $18 \mathrm{~S}$ mRNA as an internal control for each experiment, human VEGF and 18S mRNA (Guangzhou Leder Biotechnology Ltd, Co, Guangzhou, China) were amplified using gene-specific primers. The VEGF and $18 \mathrm{~S}$ mRNA primer sequences were: $\mathrm{VEGF}_{165}$, 5'-AGGAGGAGGGCAGAATCATC-3' (sense) and 5'-ATGTCCACCAGGGTCTCGAT-3' (antisense); and 18S, 5'-CCTGGATACCGCAGCTAGGA-3' (sense) and 5'-GCGGCGCAATACGAATGCCCC-3' (antisense). Reactions were run in an ABI PRISM ${ }^{\circledR} 7500$ sequence detection system under the following conditions: PCR run for 40 cycles of $95^{\circ} \mathrm{C}$ for 15 seconds, $60^{\circ} \mathrm{C}$ for 15 seconds, and $72^{\circ} \mathrm{C}$ for 32 seconds after preincubation at $95^{\circ} \mathrm{C}$ for 5 minutes. All reactions were performed in triplicate.

\section{Statistical analysis}

Statistical analysis was performed by one-factor analysis of variance (SPSS software, version 13.0, SPSS Inc, Chicago, IL). Results were expressed as the mean \pm standard deviation, and a value of $P<0.05$ was considered to be statistically significant.

\section{Results and discussion}

\section{Structural characterization of DA-Chit}

The FTIR spectrum of DA-Chit showed two strong peaks at $1659 \mathrm{~cm}^{-1}$ and $1566 \mathrm{~cm}^{-1}$ (Figure 1A), which was attributed to $-\mathrm{C}=\mathrm{O}$ vibrations and absorptions of $-\mathrm{NH}<$ and $-\mathrm{C}-\mathrm{N}-$ of the second amide group, respectively. ${ }^{27}$ This indicated that the deoxycholic acid residues were conjugated with the main chains of the chitosan through the second amide bond. The ${ }^{1} \mathrm{H}$ NMR spectrum of DA-Chit showed signals in the range of 0.6-2.3 and 3.0-5.0 ppm that were assigned to the protons of deoxycholic acid residues and chitosan (Figure 1B), respectively. ${ }^{28,29}$ Based on the integration ratio of these protons, it was determined that an average of about 3.0 deoxycholic acid residues were conjugated per 100 glucosamine units of chitosan.

\section{Preparation and properties of TAA/ DA-Chit nanoparticles}

TAA/DA-Chit nanoparticles with various TAA-loading capacities were prepared and it was found that as the TAA loading capacity increased from $12 \%$ to $82 \%$, the solubility of TAA in water increased from $0.3 \mathrm{mg} / \mathrm{mL}$ to $2.1 \mathrm{mg} / \mathrm{mL}$ (Figure 2). Improved solubility in water is important for TAA in ocular therapy. In addition, the surface charges of the nanoparticles were assessed using zeta potential analysis.
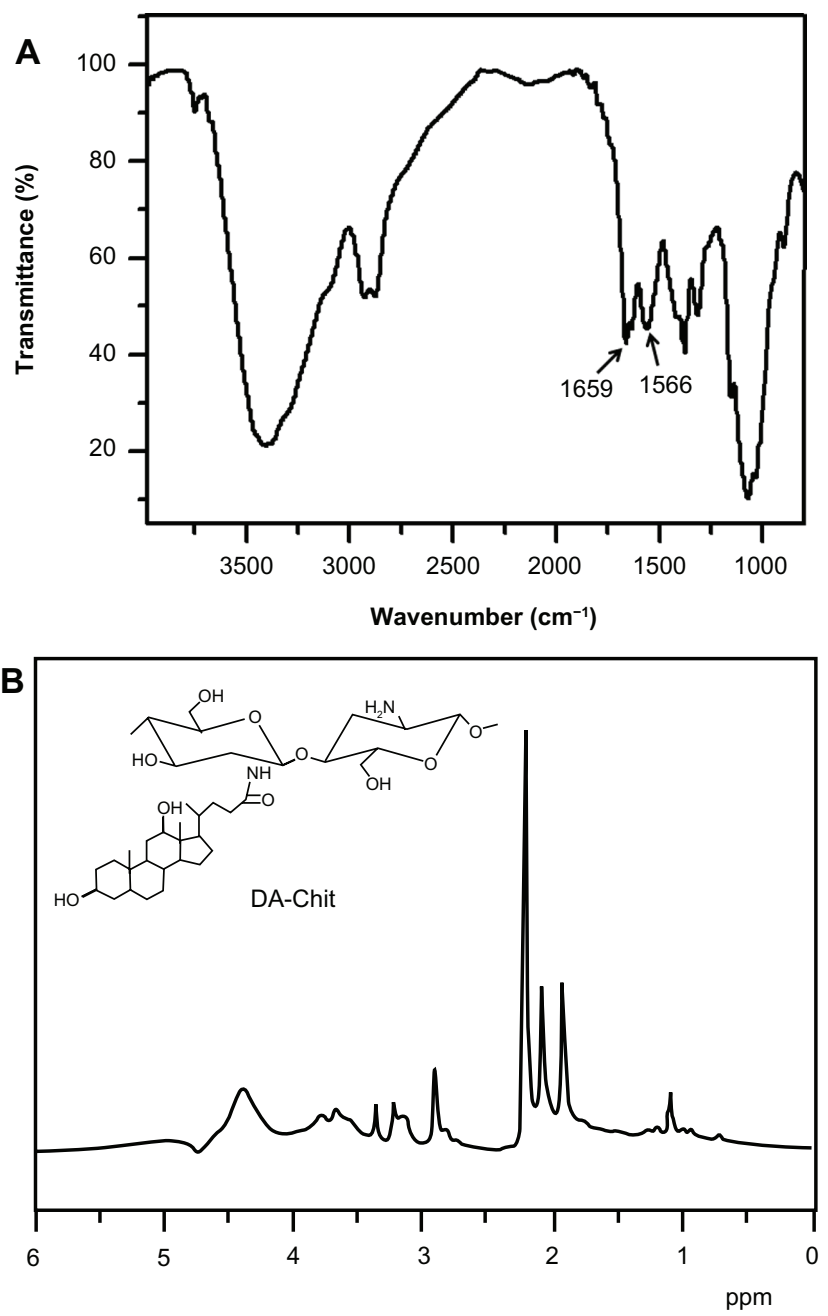

Figure I Structural characterization of DA-Chit. (A) Fourier transform infrared spectrum and (B) 'H nuclear magnetic resonance spectrum.

Abbreviation: DA-Chit, deoxycholic acid-modified chitosan.

In self-aggregations of cationic chitosan derivatives, DA-Chit nanoparticles showed a positive zeta potential at $13.4 \mathrm{mV}$, with all TAA/DA-Chit nanoparticles showing positive zeta potentials.

The morphology of DA-Chit and TAA/DA-Chit nanoparticles was investigated by transmission electron microscopy. As shown in Figure 3A, DA-Chit nanoparticles were found to have a spherical shapes approximately $50 \mathrm{~nm}$ in size. In contrast, TAA/DA-Chit nanoparticles appeared as oblate particles $100-550 \mathrm{~nm}$ in size (Figure 3B-D). In addition, TAA/DA-Chit nanoparticles became larger with increasing TAA-loading capacity. Previous researchers have reported that nanoparticles of approximately $100 \mathrm{~nm}$ and possessing a positive charge are suitable for cellular uptake in ophthalmic applications. ${ }^{30}$ Therefore, TAA/DA-Chit nanoparticles of about $100 \mathrm{~nm}$ and with a TAA-loading capacity of $29 \%$ was chosen for assessment of cytotoxicity and VEGF 


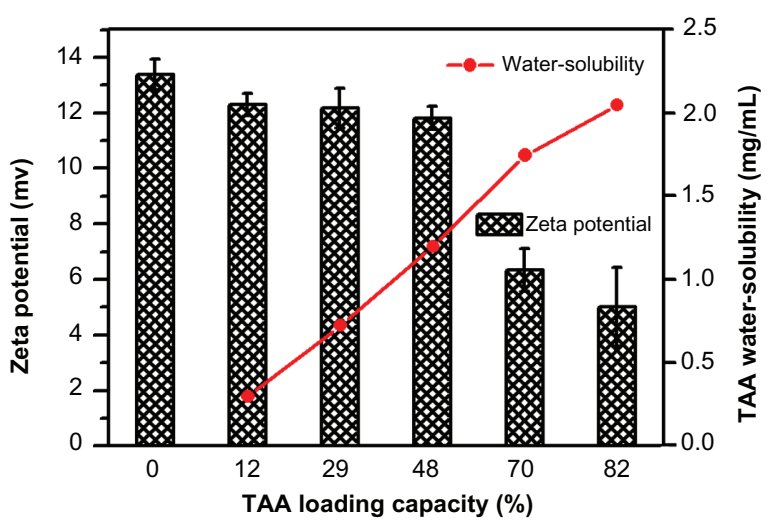

Figure 2 Water solubility of TAA and zeta potential of TAA/DA-Chit nanoparticles at various TAA-loading capacities ( $n=3$, mean \pm standard deviation).

Abbreviations: TAA, triamcinolone acetonide acetate; DA-Chit, deoxycholic acidmodified chitosan.

mRNA expression efficiency in human retinal pigment epithelial cells.

\section{Cytotoxicity and biocompatibility of DA-Chit}

The cultured cells showed typical morphology of human retinal pigment epithelial cells, being irregular, polygonal,

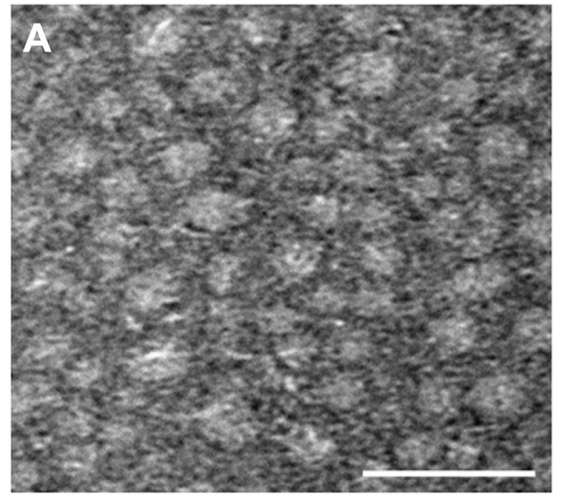

$200 \mathrm{~nm}$

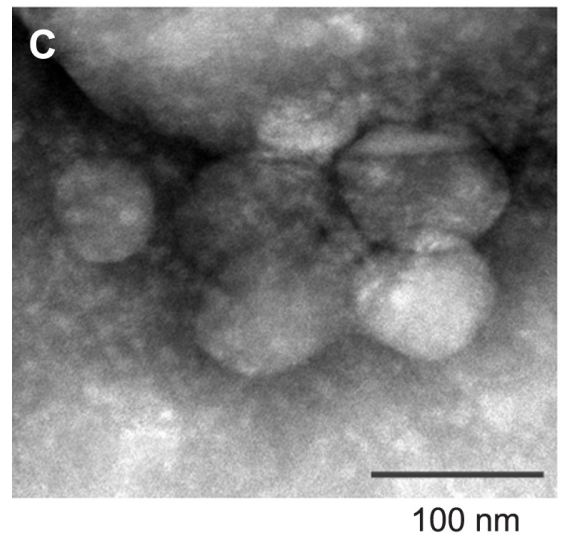

and containing melanin granules (Figure 4A), and the purple nucleoli of the cells were observed following Giemsa staining (Figure 4B). In addition, compared with the controlled cells, yellowish-brown staining of cultured cells was observed through the immunohistochemical positive reaction (Figure 4C and D), further confirming the presence of typical human retinal pigment epithelial cell characteristics. Cell viability after incubation with DA-Chit at various concentrations for 24 hours was more than $94.3 \%$ at concentrations below $1.0 \mathrm{mg} / \mathrm{mL}$ (Figure 5), indicating extremely low cytotoxicity and good biocompatibility of DA-Chit. This feature would be an advantage for the controlled release of ocular drugs.

\section{Cytotoxicity of TAA/DA-Chit nanoparticles}

Although triamcinolone acetonide analogs have demonstrated an inhibitory effect on VEGF upregulation in ocular pathology, their cytotoxicity should be considered. ${ }^{13,14}$ For example, triamcinolone acetonide is toxic to human retinal pigment epithelial cells in concentrations from $0.01 \mathrm{mg} / \mathrm{mL}$ to $1 \mathrm{mg} / \mathrm{mL}$, resulting in apoptosis. ${ }^{31,32}$ The cytotoxicity of
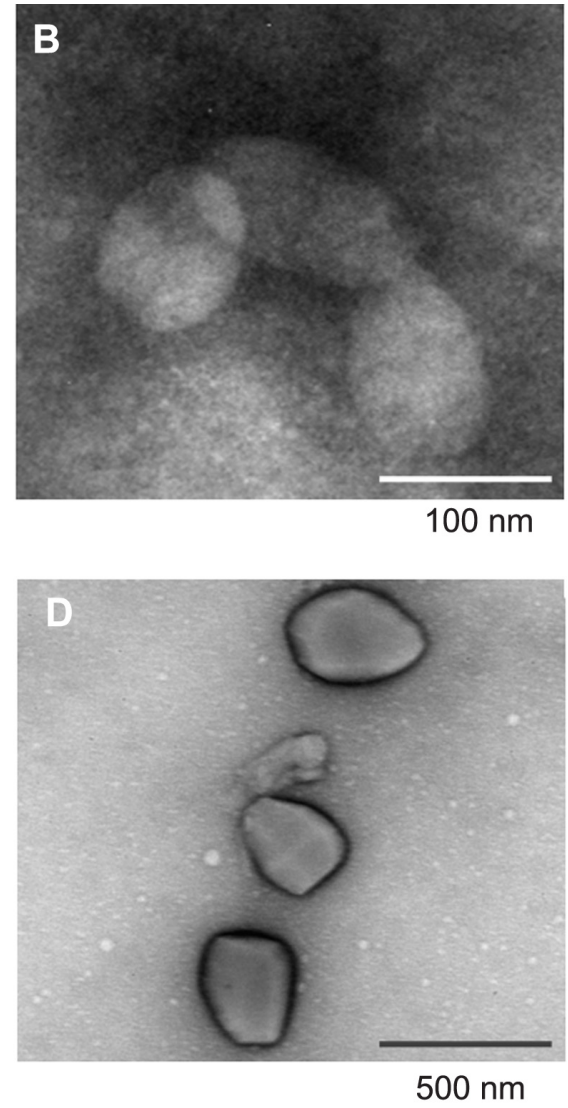

Figure 3 Transmission electron microscopy images of $(\mathbf{A})$ deoxycholic acid-modified chitosan nanoparticles and triamcinolone acetonide acetate/deoxycholic acid-modified chitosan nanoparticles with different triamcinolone acetonide acetate-loading capacities, ie, (B) $12 \%$, (C) $29 \%$, and (D) $82 \%$. 

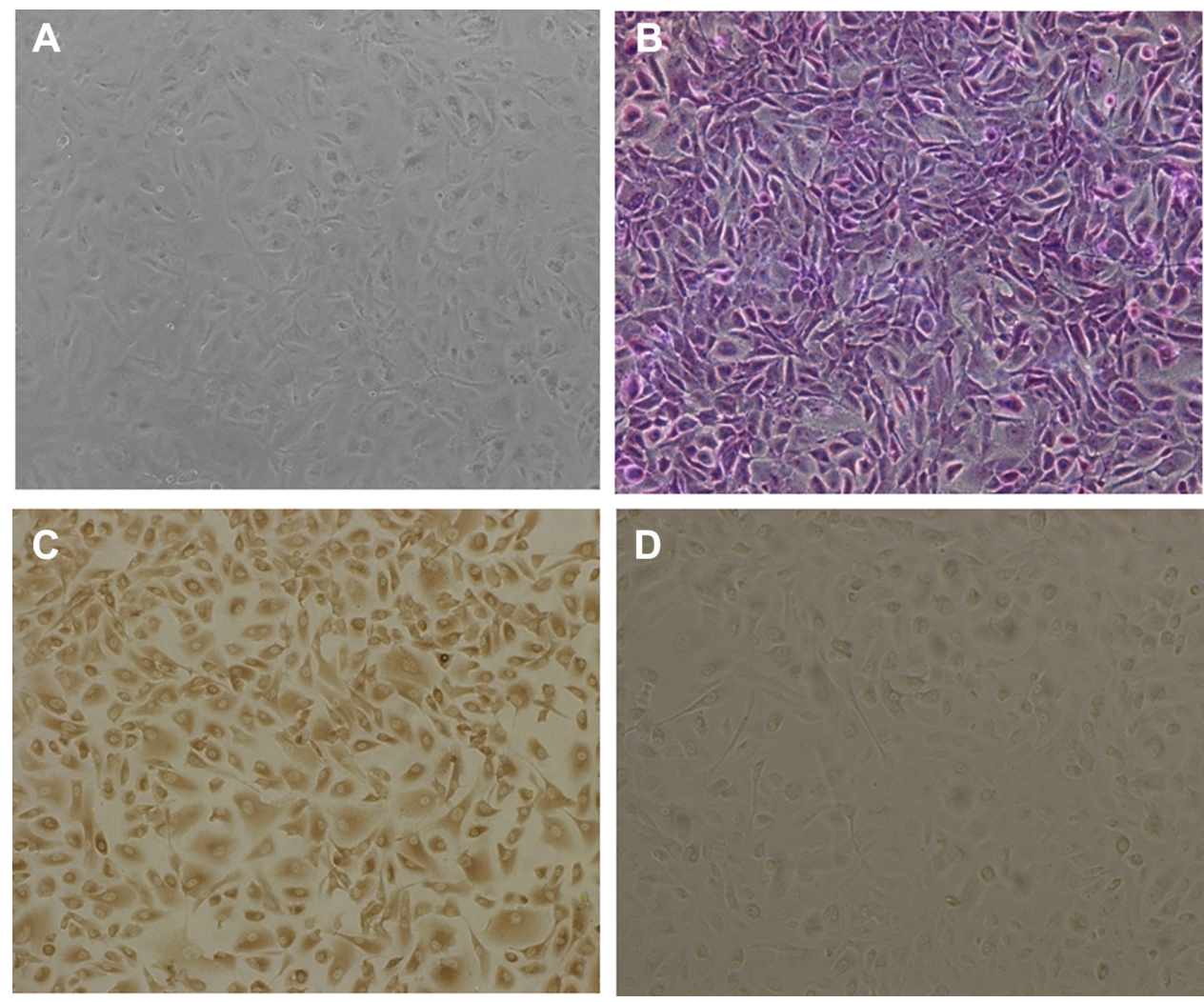

Figure 4 Morphology of cultured hRPE cells. (A) primary cultured hRPE cells, (B) Giemsa staining hRPE cells, (C) immunocytochemical staining hRPE cells, and (D) hRPE cells lacking immunohistochemical staining in control preparation $(\times 100)$.

Abbreviation: hRPE, human retinal pigment epithelial.

TAA/DA-Chit nanoparticles was thus evaluated using the CCK-8 assay. ${ }^{26}$ After human retinal pigment epithelial cells had been incubated with TAA at $0.1 \mathrm{mg} / \mathrm{mL}$ for $1-5$ days, cell viability decreased from $78.3 \%$ to $40.4 \%$ (Figure 6), suggesting strong cytotoxicity. In contrast, cell viability in the TAA/

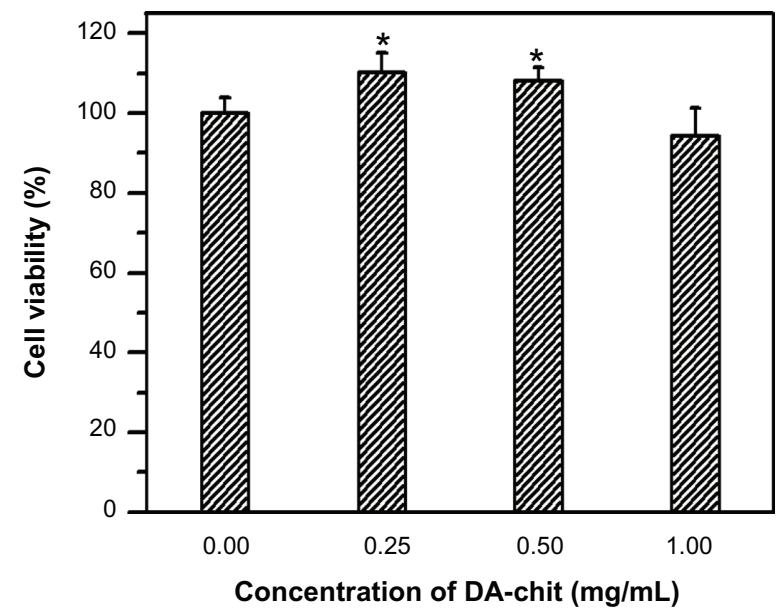

Figure 5 Cytotoxicity assay for DA-Chit at various concentrations compared with control hRPE cells (after a 24-hour incubation period, $n=5$, mean \pm standard deviation, $* P<0.05$, statistically significant difference versus controls).

Abbreviations: DA-Chit, deoxycholic acid-modified chitosan; hRPE, human retinal pigment epithelial.
DA-Chit nanoparticle-treated group was higher than that in the TAA-treated group. This indicates that TAA cytotoxicity was significantly reduced after encapsulation in TAA/ DA-Chit nanoparticles, which would be of benefit in ocular therapy. The low cytotoxicity of TAA/DA-Chit nanoparticles

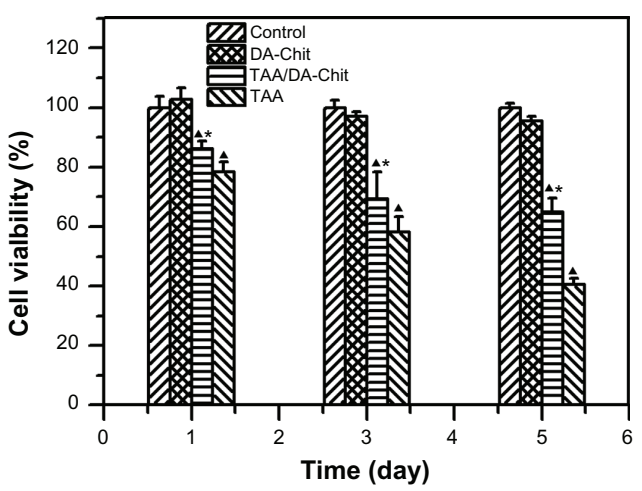

Figure 6 Cytotoxicity assay for DA-Chit, TAA, and TAA/DA-Chit nanoparticles compared with controls in human retinal pigment epithelial cells (at different incubation times and TAA concentrations of $0.1 \mathrm{mg} / \mathrm{mL}$ for TAA and TAA/DAChit nanoparticles, ${ }^{A} P<0.05$, statistically significant difference versus controls, $* P<0.05$, statistically significant difference versus the TAA group, $\mathrm{n}=5$, mean \pm standard deviation).

Abbreviations: TAA, triamcinolone acetonide acetate; DA-Chit, deoxycholic acidmodified chitosan. 
may be related to the extremely low cytotoxicity of DA-Chit nanoparticles, with cell viability above 95.6\% after 5 days (Figure 6), as well as controlled release of TAA from the intracellular nanoparticles.

\section{Cellular uptake efficiency of FITC-labeled DA-Chit nanoparticles}

It is known that nanoparticles enter cells via endocytosis and macropinocytosis, and cellular uptake efficiency is mainly dependent on nanoparticle concentration and incubation time. ${ }^{33,34}$ Cellular uptake efficiency was investigated using fluorescently labeled FITC/DA-Chit nanoparticles instead of TAA/DA-Chit nanoparticles. Fluorescent images of the human retinal pigment epithelial cells showed that strong green fluorescent density in the cells increased with increasing nanoparticle concentration and incubation time (Figure 7I and II), implying that FITC/DA-Chit nanoparticles were continuously taken up by the cells during incubation.

(I)
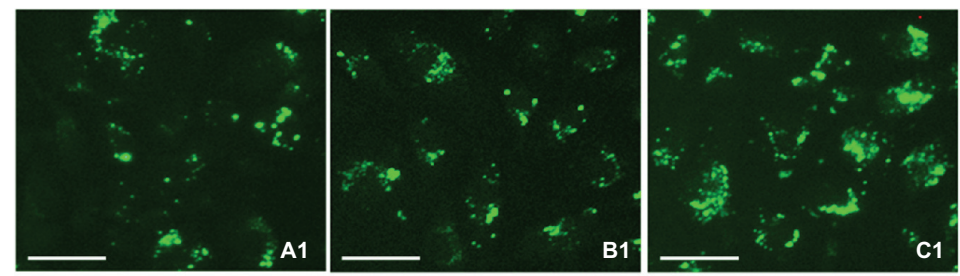

B2

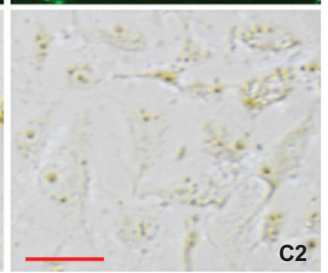

(II)
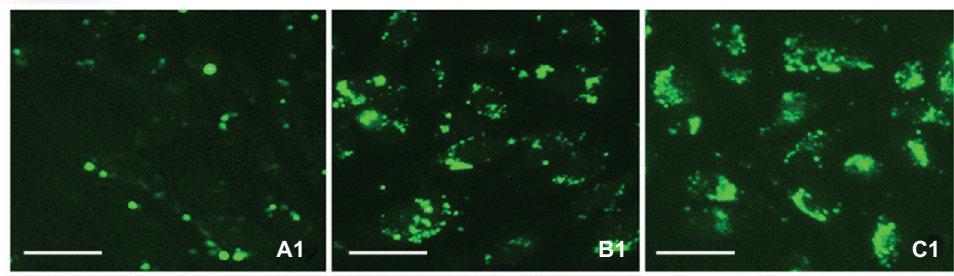

(III)
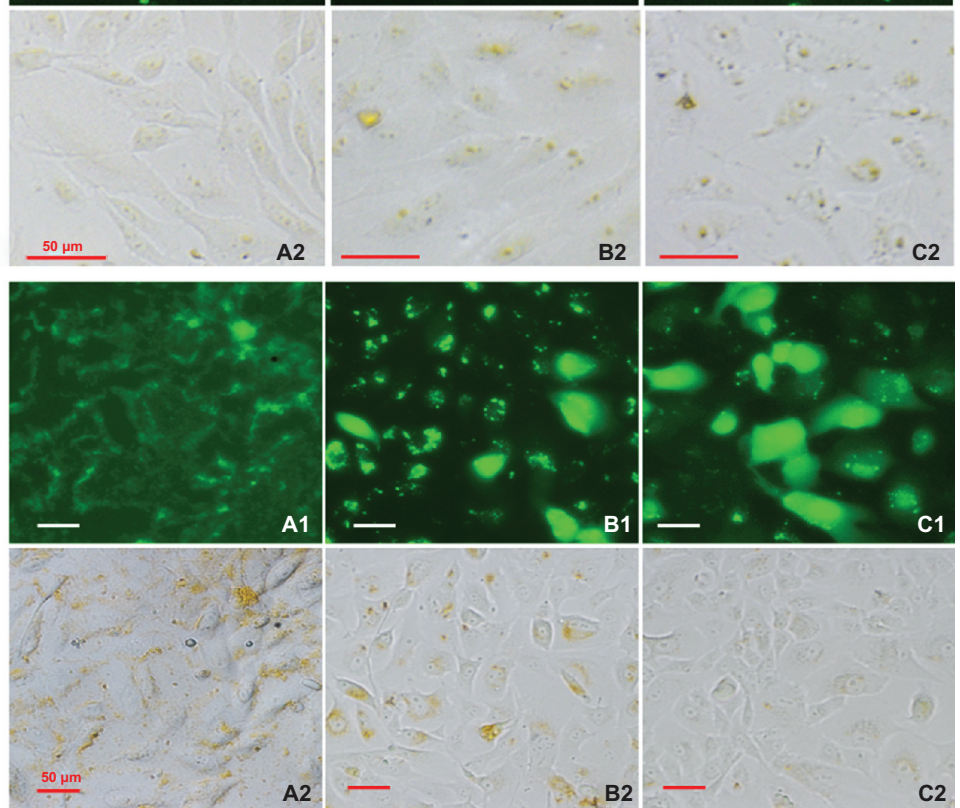

Figure 7 Typical fluorescence images of (I) hRPE cells incubated with FITC/DA-Chit nanoparticles for 24 hours at concentrations of (A) $0.3 \mathrm{mg} / \mathrm{mL}$, (B) $0.5 \mathrm{mg} / \mathrm{mL}$, and (C) $1.0 \mathrm{mg} / \mathrm{mL}$; (II) hRPE cells incubated with FITC/DA-Chit nanoparticles at $1.0 \mathrm{mg} / \mathrm{mL}$ for (A) 3 hours, (B) 6 hours, and (C) 24 hours. (III) hRPE cells further incubated for different times following removal of FITC/DA-Chit nanoparticles from the culture medium, ie, (A) one day, (B) 3 days, and (C) 5 days, after incubation with I.0 mg/mL of FITC/DA-Chit nanoparticles for 24 hours (scale bar $50 \mu \mathrm{m}$, I fluorescence field images, 2 bright field images).

Abbreviations: hRPE, human retinal pigment epithelial; FITC/DA-Chit, fluorescein isothiocyanate-labeled deoxycholic acid-modified chitosan. 
In addition, fluorescence images of the human retinal pigment epithelial cells that were further incubated following removal of the FITC/DA-Chit nanoparticles from the culture medium showed that the fluorescent region along the cell membrane on the first day spread into the cells by the third day, so that most cells were dyed completely green by the fifth day (Figure 7IIIA-C). This progression suggests that green FITC was released in a controlled manner from the FITC/DA-Chit nanoparticles and spread throughout the cells. This is perhaps because DA-Chit was degraded by lysozyme in the cells, ${ }^{35,36}$ as well as FITC diffusing from the nanoparticles. According to the literature, yellow granules that appeared in bright field images were from colocalization of FITC/DA-Chit nanoparticles with lysosomes. ${ }^{33}$ After the human retinal pigment epithelial cells were incubated for a further 5 days, many yellow granules disappeared (7IIIC2), indicating that the nanoparticles became dispersed or disaggregated in the cytoplasm. This phenomenon has also been observed when cholanic acid-modified glycol chitosan nanoparticles are taken up in HeLa cells. ${ }^{33}$

Analysis of the cellular uptake efficiency of FITC/ DA-Chit nanoparticles by flow cytometry revealed that, after 24 hours of incubation, the number of cells taking up the nanoparticles increased clearly with an increase in nanoparticle concentration from $0.3 \mathrm{mg} / \mathrm{mL}$ to $1.0 \mathrm{mg} / \mathrm{mL}$ (Figure $8 \mathrm{~A}$ ). The proportion of cells accumulating nanoparticles was $75.4 \%, 94.6 \%$, and $98.2 \%$ with increasing concentration (Figure 8C), indicating that the nanoparticles were taken up
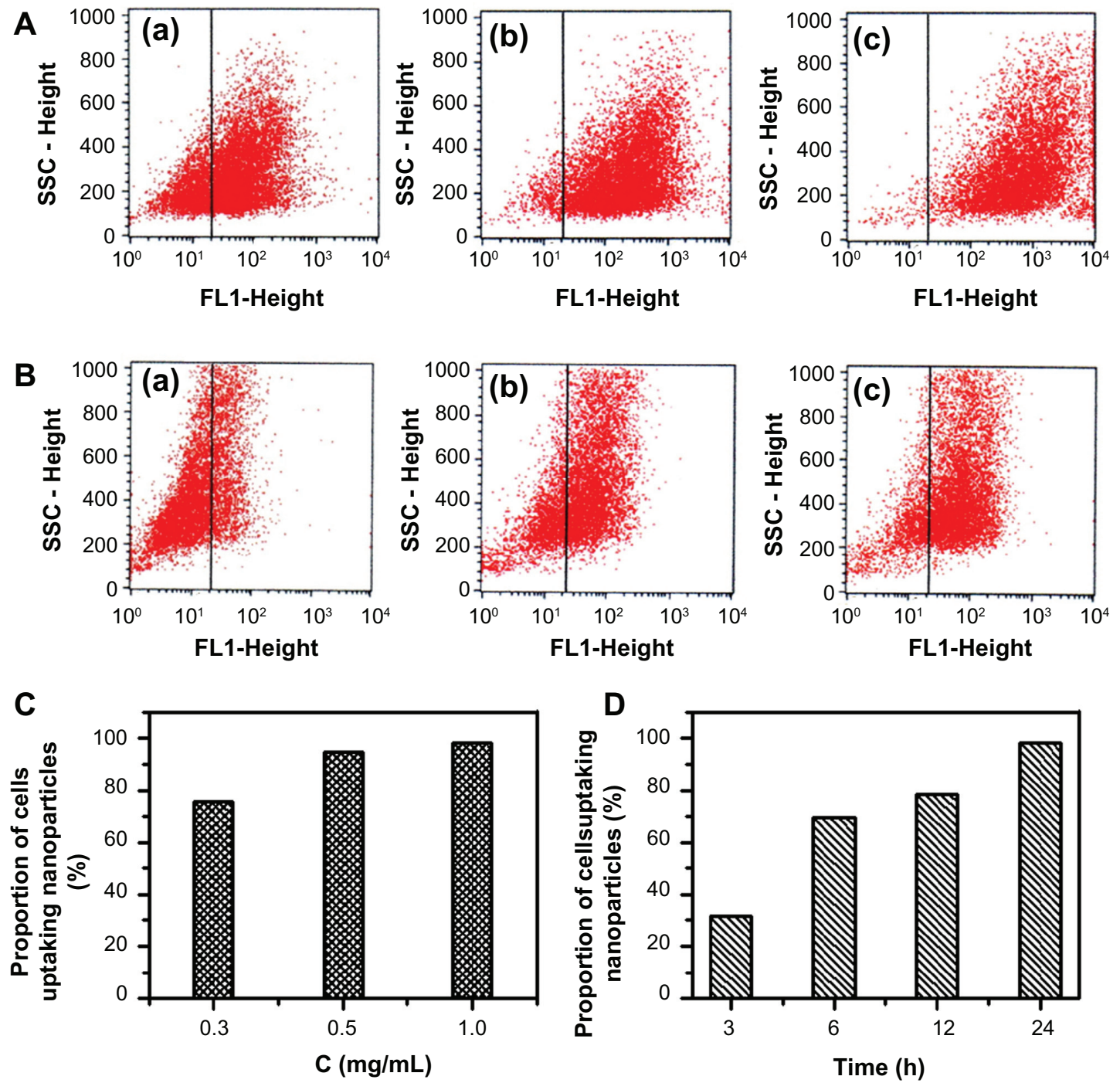

Figure 8 Cellular uptake efficiency in response to FITC/DA-Chit nanoparticles by flow cytometry analysis. (A) hRPE cells incubated with FITC/DA-Chit nanoparticles for 24 hours at concentrations of (a) $0.3 \mathrm{mg} / \mathrm{mL}$, (b) $0.5 \mathrm{mg} / \mathrm{mL}$, and (c) $1.0 \mathrm{mg} / \mathrm{mL}$. (B) hRPE cells incubated with FITC/DA-Chit nanoparticles at I.0 mg/mL for (a) 3 hours, (b) 6 hours, and (c) 12 hours. (C) Proportions of hRPE cells taking up FITC/DA-Chit versus nanoparticle concentrations. (D) Proportions of hRPE cells taking up FITC/ DA-Chit nanoparticles versus incubation time.

Abbreviations: hRPE, human retinal pigment epithelial; FITC/DA-Chit, fluorescein isothiocyanate-labeled deoxycholic acid-modified chitosan; SSC, side scatter. 
by human retinal pigment epithelial cells throughout 24 hours of incubation with $1.0 \mathrm{mg} / \mathrm{mL}$ nanoparticles. Further, it was observed that the proportion of cells taking up nanoparticles at $1 \mathrm{mg} / \mathrm{mL}$ was dependent on incubation time (Figure $8 \mathrm{~B}$ and Figure $8 \mathrm{~A}-\mathrm{c}$ ), showing $31.5 \%, 69.4 \%, 78.5 \%$, and $98.2 \%$ at $3,6,12$, and 24 hours, respectively (Figure 8D). These results are in agreement with the present fluorescent micrographic results, indicating that FITC was delivered effectively into cells by the FITC/DA-Chit nanoparticles, an effect attributed to the favorable cellular affinity of the main chains of chitosan and deoxycholic acid residues of DA-Chit macromolecules.

\section{VEGF mRNA expression efficiency}

VEGF is an important angiogenic stimulator and a potent vascular permeability factor in intraocular disease. ${ }^{37,38}$ Upregulation of VEGF has been found to correlate with the presence of diabetic macular edema and proliferative diabetic retinopathy. ${ }^{39}$ Previous studies have reported that triamcinolone acetonide produces functional improvement in patients with diabetic retinopathy by inhibiting upregulation of VEGF. ${ }^{10,13,14}$ The effects of free TAA and TAA/DA-Chit nanoparticles were investigated here as another possibly useful application of corticosteroids.

Because $\mathrm{VEGF}_{165}$ is the major VEGF isoform and the predominant molecular species produced by a number of normal and transformed cells, ${ }^{40}$ the inhibitory effect on VEGF $_{165}$ upregulation was evaluated by real-time RT-PCR assay in human retinal pigment epithelial cells (Figure 9). Interestingly, compared with controls, the TAA/DA-Chit nanoparticles decreased VEGF mRNA expression, while upregulated VEGF mRNA expression was observed in the TAA-treated group. With the aid of the literature, ${ }^{41}$ it is known that triamcinolone acetonide regulates VEGF in a concentration-dependent manner, such that triamcinolone acetonide exerts a biphasic effect on retinal pigment epithelial cell proliferation, stimulating cell growth at lower concentration (lower than $1 \mu \mathrm{M}$, ie, $0.44 \mu \mathrm{g} / \mathrm{mL}$ ) but inhibiting cell growth at higher concentration (higher than $100 \mu \mathrm{M}$, ie, $44 \mu \mathrm{g} / \mathrm{mL}$ ). Accordingly, upregulation of VEGF mRNA expression by free TAA is probably a result of very low TAA uptake by human retinal pigment epithelial cells due to the extremely low solubility of TAA in water. However, the water solubility of TAA was effectively improved by encapsulation into DA-Chit nanoparticles (Figure 2). In addition to effective delivery of TAA to human retinal pigment epithelial cells and subsequent controlled release of TAA by TAA/DA-Chit nanoparticles, the amount of TAA entering the cells increased,

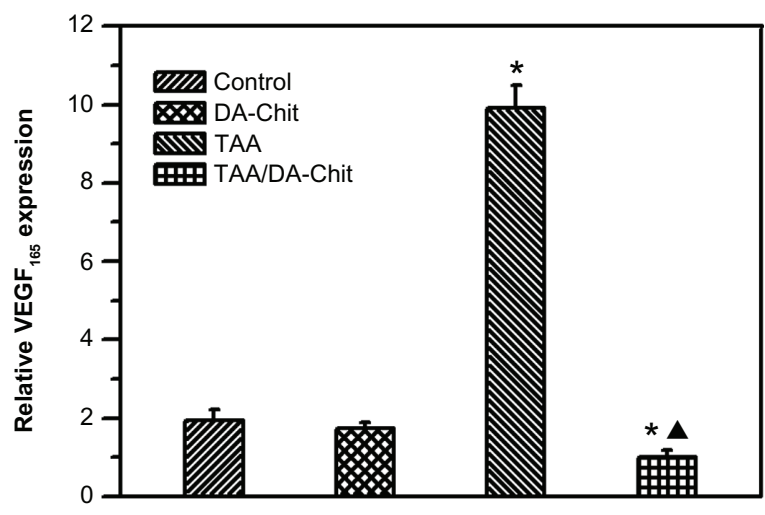

Figure $9 \mathrm{VEGF}_{165}$ expression in hRPE cells assessed by real-time reverse transcription polymerase chain reaction ( $* P<0.01$, statistically significant difference versus controls; ${ }^{\wedge} P<0.05$, statistically significant difference versus the TAA-treated group).

Abbreviations: hRPE, human retinal pigment epithelial; TAA, triamcinolone acetonide acetate; DA-Chit, deoxycholic acid-modified chitosan; VEGF, vascular endothelial growth factor.

and the release process for TAA was more potent and longlasting than for free TAA, resulting in downregulation of VEGF mRNA expression. Similar improvement in drugdelivery efficiency in response to polymeric nanoparticles has also been reported by previous researchers. ${ }^{42}$

The most common injection doses of triamcinolone acetonide used in ophthalmic practice are 4-20 mg. ${ }^{10}$ Because the vitreous volume in humans is about $4 \mathrm{~mL},{ }^{32}$ the equivalent vitreous concentration of this corticosteroid thus corresponds to $1-5 \mathrm{mg} / \mathrm{mL}$. Although the experimental TAA concentration in the present TAA/DA-Chit nanoparticles $(0.1 \mathrm{mg} / \mathrm{mL})$ was much less than the clinical concentration of triamcinolone acetonide, downregulation of VEGF mRNA expression was significant. Consequently, potential therapeutic advantages of these TAA/DA-Chit nanoparticles, if administered by vitreous injection for diabetic retinopathy, might be anticipated due to the resulting downregulation of VEGF mRNA expression with attendant low cytotoxicity, as observed in these human retinal pigment epithelial cells.

\section{Conclusion}

TAA/DA-Chit nanoparticles were prepared through a selfassembly mechanism. When the TAA-loading capacity increased from $12 \%$ to $82 \%$, the solubility of TAA in water was found to increase from 0.3 to $2.1 \mathrm{mg} / \mathrm{mL}$. TAA/DA-Chit nanoparticles showed oblate shapes, ranging from $100 \mathrm{~nm}$ to $550 \mathrm{~nm}$ in size and with positive zeta potentials. CCK-8 assay indicated that DA-Chit was nontoxic and TAA/DAChit nanoparticles showed low toxicity to human retinal pigment epithelial cells. Uptake of FITC/DA-Chit nanoparticles by human retinal pigment epithelial cells was confirmed by both inverted fluorescence microscopy and flow cytometry. 
These nanoparticles imposed a downregulating effect on cellular VEGF mRNA expression, as shown by real-time RT-PCR assessment, suggesting potential and advantageous utility in future treatment of diabetic retinopathy.

\section{Acknowledgments}

This work was supported by the National Natural Science Foundation of China (20974130, 20574089) and the Natural Science Foundation of Guangdong Province, China (2009B020313001).

\section{Disclosure}

The authors report no conflicts of interest in this work.

\section{References}

1. Scanlon PH. Diabetic retinopathy. Medicine. 2010;38:656-660.

2. Fante RJ, Durairaj VD, Oliver SCN. Diabetic retinopathy: An update on treatment. Am J Med. 2010;123:213-216.

3. Alghadyan AA. Diabetic retinopathy - an update. Saudi J Ophthalmol. 2011;25:99-111.

4. Kim YH, Chung IY, Choi MY, et al. Triamcinolone suppresses retinal vascular pathology via a potent interruption of proinflammatory signalregulated activation of VEGF during a relative hypoxia. Neurobiol Dis. 2007;26:569-576.

5. Chung HS, Harris A, Halter PJ, et al. Regional differences in retinal vascular reactivity. Invest Ophthalmol Vis Sci. 1999;40:2448-2453.

6. Ishida $\mathrm{S}$, Usui $\mathrm{T}$, Yamashiro $\mathrm{K}$, et al. $\mathrm{VEGF}_{164}$ is proinflammatory in the diabetic retina. Invest Ophthalmol Vis Sci. 2003;44:2155-2162.

7. Funatsu H,Yamashita H, Noma H. Risk evaluation of outcome of vitreous surgery for proliferative diabetic retinopathy based on vitreous level of vascular endothelial growth factor and angiotensin II. $\mathrm{Br} J$ Ophthalmol. 2004;88:1064-1068.

8. Ogata N, Nishikawa M, Nishimura T, Mitsuma Y, Matsumura M. Unbalance vitreous levels of pigment epithelium-derived factor and vascular endothelial growth factor in diabetic retinopathy. $\mathrm{Am} J$ Ophthalmol. 2002;134:348-353.

9. Sydorova M, Lee MS. Vascular endothelial growth factor in virtreous and serum of patients with either proliferative diabetic retinopathy or proliferative vitreoretinopathy. Ophthalmic Res. 2005;37:188-190.

10. Jermak CM, Dellacroce JT, Heffez J, Peyman GA. Triamcinolone acetonide in ocular therapeutics. Surv Ophthalmol. 2007;52:503-522.

11. Jonas JB, Kreissig I, Degenring R. Intravitreal triamcinolone acetonide for treatment of intraocular proliferative, exudative, and neovascular diseases. Prog Retinal Eye Res. 2005;24:587-611.

12. Ozdek SC, Aydin B, Gurelik G, Bahceci U, Hasanreisoglu B. Effects of intravitreal triamcinolone injection on macular edema and visual prognosis in central retinal vein occlusion. Int Ophthalmol. 2006;16:27-34.

13. Kim YH, Choi MY, Kim YS, et al. Triamcinolone acetonide protects the rat retina from STZ-induced acute inflammation and early vascular leakage. Life Sci. 2007;81:1167-1173.

14. Zhang X, Bao S, Lai D, Rapkins RW, Gillies MC. Intravitreal triamcinolone acetonide inhibits breakdown of the blood-retinal barrier through differential regulation of VEGF-A and its receptors in early diabetic rat retinas. Diabetes. 2008;57:1026-1033.

15. Kim SY, Yang J, Lee YC, Park YH. Effect of a single intraoperative sub-Tenon injection of triamcinolone acetonide on the progression of diabetic retinopathy and visual outcomes after cataract surgery. $J$ Cataract Refract Surg. 2008;34:823-826.

16. Oh J, Jung YS, Kim MY, et al. The effect of short-term exposure of triamcinolone acetonide on fibroblasts and retinal pigment epithelial cells. Acta Ophthalmol Scand. 2007;85:786-790.
17. Joans JB. Intravitreal triamcinolone acetonide for treatment of intraocular oedematous and neovascular diseases. Acta Ophthalmol Scand. 2005; 83:645-663.

18. Liu Z, Jiao Y, Wang Y, Zhou C, Zhang Z. Polysaccharides-based nanoparticles as drug delivery systems. Adv Drug Deliv Rev. 2008;60: $1650-1662$.

19. Yang L, Kuang J, Wang J, Li Z, Zhang L. Loading and in vitro controlled release of indomethacin using amphiphilic cholesterylbearing carboxymethylcellulose derivatives. Macromol Biosci. 2008;8: 279-286.

20. Yang L, Zhang B, Wen L, Liang Q, Zhang L. Amphiphilic cholesteryl grafted sodium alginate derivative: Synthesis and self-assembly in aqueous solution. Carbohydr Polym. 2007;68:218-225.

21. Fuente M, Ravina M, Paolicelli P, Sanchez A, Seijo B, Alonso MJ. Chitosan-based nanostructures: a delivery platform for ocular therapeutics. Adv Drug Deliv Rev. 2010;62:100-117.

22. Yang L, Lan Y, Guo H, et al. Ophthalmic drug-loaded $N, O$-carboxymethyl chitosan hydrogels: synthesis, in vitro and in vivo evaluation. Acta Pharmacol Sin. 2010;31:1625-1634.

23. Liu W, Hu M, Liu W, Xue C, Xu H, Yang X. Investigation of the carbopol gel of solid lipid nanoparticles for the transdermal iontophoretic delivery of triamcinolone acetonide acetate. Int J Pharm. 2008;364: 135-141.

24. Lee KY, Jo WH, Kwon IC, Kim YH, Jeong SY. Structural determination and interior polarity of self-aggregates prepared from deoxycholic acidmodified chitosan in water. Macromolecules. 1998;31:378-383.

25. Gottlieb HE, Kotlyar V, Nudelman A. NMR chemical shifts of common laboratory solvents as trace impurities. J Org Chem. 1997;62: $7512-7515$.

26. Li XT, Zhang Y, Chen GQ. Nanofibrous polyhydroxyalkanoate matrices as cell growth supporting materials. Biomaterials. 2008;29: 3720-3728.

27. Wu J. Techniques and Applications of Modern FTIR Spectroscopy. Beijing, China: Science Press; 1994.

28. Kim C, Lee SC, Kang SW, Kwon IC, Kim YH, Jeong SY. Synthesis and the micellar characteristics of poly(ethylene oxide)-deoxycholic acid conjugates. Langmuir. 2000;16:4792-4797.

29. Luckachan GE, Pillai CKS. Chitosan/oligo L-lactide graft copolymers: effect of hydrophobic side chains on the physico-chemical properties and biodegradability. Carbohyr Polym. 2006;64:254-266.

30. Pignatello R, Bucolo C, Ferrara P, Maltese A, Puleo A, Puglisi G. Eudragit RS100 nanosuspensions for the ophthalmic controlled delivery of ibuprofen. Eur J Pharm Sci. 2002;16:53-61.

31. Narayanan R, Mungcal JK, Kenney MC, Seigel GM, Kuppermann BD. Toxicity of triamcinolone acetonide on retinal neurosensory and pigment epithelial cells. Invest Ophthalmol Vis Sci. 2006;47: $722-728$.

32. Yeung CK, Chan KP, Chiang SWY, Pang CP, Lam DSC. The toxic and stress responses of cultured human retinal pigment epithelium (ARPE19) and human glial cells (SVG) in the presence of triamcinolone. Invest Ophthalmol Vis Sci. 2003;44:5293-5300.

33. Nam HY, Kwon SM, Chung H, et al. Cellular uptake mechanism and intracellular fate of hydrophobically modified glycol chitosan nanoparticles. J Control Release. 2009;135:259-267.

34. Park JS, Han TH, Lee KY, et al. N-acetyl histidine-conjugated glycol chitosan self-assembled nanoparticles for intracytoplasmic delivery of drugs: endocytosis, exocytosis and drug release. J Control Release. 2006;115:37-45.

35. Tomihata K, Ikada Y. In vitro and in vivo degradation of films of chitin and its deacetylated derivatives. Biomaterials. 1997;18:567-575.

36. Verheul RJ, Amidi M, Steenbergen MJ, Riet E, Jiskoot W, Hennink WE. Influence of the degree of acetylation on the enzymatic degradation and in vitro biological properties of trimethylated chitosans. Biomaterials. 2009;30:3129-3135.

37. Kwak N, Okamoto N, Wood JM, Campochiaro PA. VEGF is major stimulator in model of choroidal neovascularization. Invest Ophthalmol Vis Sci. 2000;41:3158-3164. 
38. Senger DR, Perruzzi CA, Feder J, Dvorak HF. A highly conserved vascular permeability factor secreted by a variety of human and rodent tumor cell lines. Cancer Res. 1986;46:5629-5632.

39. Funatsu H, Yamashita H, Ikeda T, Mimura T, Eguchi S, Hori S. Vitreous levels of interleukin- 6 and vascular endothelial growth factor are related to diabetic macular edema. Ophthalmology. 2003;110:1690-1696.

40. Kim YS, Jung DH, Kim NH, et al. KIOM-79 inhibits high glucose or AGEs-induced VEGF expression in human retinal pigment epithelial cells. J Ethnopharm. 2007;112:166-172.
41. Matsuda S, Gomi F, Oshima Y, Tohyama M, Tano Y. Vascular endothelial growth factor reduced and connective tissue growth factor induced by triamcinolone in ARPE19 cells under oxidative stress. Invest Ophthalmol Vis Sci. 2005;46:1062-1068.

42. Das S, Haddadi A, Veniamin S, Samuel J. Delivery of rapamycinloaded nanoparticle down regulates ICAM-1 expression and maintains an immunosuppressive profile in human $\mathrm{CD} 34 \mathrm{p}$ progenitor-derived dendritic cells. J Biomed Mater Res. 2008;85A:983-992.

\section{Publish your work in this journal}

The International Journal of Nanomedicine is an international, peerreviewed journal focusing on the application of nanotechnology in diagnostics, therapeutics, and drug delivery systems throughout the biomedical field. This journal is indexed on PubMed Central, MedLine, CAS, SciSearch $\AA$, Current Contents ${ }^{\circledR} /$ Clinical Medicine,
Journal Citation Reports/Science Edition, EMBase, Scopus and the Elsevier Bibliographic databases. The manuscript management system is completely online and includes a very quick and fair peer-review system, which is all easy to use. Visit http://www.dovepress.com/ testimonials.php to read real quotes from published authors. 